\title{
DESEMPENHO ECONÔMICO E MUDANÇAS INSTITUCIONAIS NO ESTADO BRASILEIRO ENTRE 1995 E 2002
}

\author{
Adriana Kirchof de Brum ${ }^{1}$ \\ Airton Pinto de Moura ${ }^{2}$
}

\begin{abstract}
RESUMO
A análise do efeito das instituições sobre o desempenho econômico dos países vem ganhando destaque cada vez maior nos estudos de economia realizados no Brasil nos últimos anos. O postulado básico de que "as instituições importam" traz à tona a discussão de uma série de questões para explicar por que determinadas economias crescem a taxas maiores do que outras. Sob o ponto de vista institucionalista, o desempenho econômico surge como consequência de uma determinada configuração institucional, em que o aspecto histórico é relevante, uma vez que esse reflete, direta ou indiretamente, o tipo de postura a ser tomada pelos agentes nas esferas econômica, política, social e inovativa. Nessas condições, o presente estudo tem por objetivo analisar as mudanças institucionais ocorridas entre 1995 e 2002, salientando as principais mudanças no que se refere à configuração do regime de Estado e sua influência no desempenho da economia brasileira durante o período.
\end{abstract}

Palavras-chave: Mudanças Institucionais. Regime de Estado. Desempenho Econômico.

\begin{abstract}
The analysis of the effect of institutions on economic performance of countries has been gaining increasing prominence in the economic studies conducted in Brazil in recent years. The basic postulate that "institutions matter " raises the discussion of a series of questions to explain why some economies grow at rates higher than others. From the institutional point of view, the economic performance is a consequence of a particular institutional setting in which the historical aspect is important, since this reflects, directly or indirectly, the kind of attitude to be taken by agents in the economic, political, social and innovative. Under these conditions, this study aims to examine the institutional changes that occurred between 1995 and 2002, highlighting the major changes regarding the configuration of the system state and its influence on the Brazilian economy during the period.
\end{abstract}

Keywords: Institutional Change. State regime. Economic Performance.

\footnotetext{
${ }^{1}$ Doutora em Economia pela Universidade Federal do Rio Grande do Sul (UFRGS). Professora e pesquisadora da Universidade Federal da Grande Dourados (UFGD). E-mail: adriana@focoeconomico.com.br

${ }^{2}$ Doutor em Economia pela Universidade Federal do Rio Grande do Sul (UFRGS). Professor no Curso de Administração da Universidade Estadual de Mato Grosso do Sul (UEMS). E-mail: atendimento@professorairton.com.br
}

Recebido em: 25/08/2011

Aceito em: 08/02/2012 


\section{INTRODUÇÃO}

Em 2008, a economia mundial vivenciou uma das maiores crises da história decorrente da bolha no mercado imobiliário norte-americano, a qual evidenciou a fragilidade de uma série de instituições. Tal episódio teve início em 2001, quando, no intuito de proteger os investidores, houve orientação para que esses direcionassem seus recursos para o setor imobiliário. Incentivados pela política de taxas de juros baixas e de redução de despesas financeiras, verificou-se uma expansão considerável do endividamento com base em um sistema de concessão de hipotecas subprimes de alto risco e de taxa variável concedidos ao público de baixa renda ou sem emprego.

Há que se considerar em um passo seguinte o fato de os bancos disponibilizarem a oferta de derivativos negociáveis no mercado financeiro através da transformação em títulos livremente negociáveis que passaram a ser vendidos para outros bancos e instituições financeiras pelo mundo afora. A partir disso, bastou que o Federal Reserve aumentasse a taxa de juros em 2005 sob pretexto de diminuir a inflação para que os preços dos imóveis fossem reduzidos e desencadeassem um processo de inadimplência em massa, ao tornar impossível o refinanciamento dos clientes, bem como impossibilitar a renegociação desses títulos no sistema bancário internacional.

Como consequências das grandes perdas sofridas pelos empréstimos hipotecários subprime, a primeira crise financeira do século XXI teve como causa principal a subprecificação do risco em todo o mundo, anomalia que se agravou aos poucos desde a década de 1990 até atingir níveis praticamente históricos em 2007.

Na América Latina, a crise econômica levou à utilização de inúmeros instrumentos de política fiscal com o objetivo de mitigar seus efeitos. Além de redução de impostos, adotaram-se medidas de apoio ao setor produtivo, mormente orientadas às pequenas e médias empresas e ao setor agrícola, bem como ampliados gastos com infraestrutura, incluindo programas habitacionais.

Em se tratando de Brasil, os impactos mais imediatos e severos da crise foram a queda da bolsa de valores, a subida do risco Brasil e a desvalorização do câmbio em virtude da venda de papéis brasileiros pelos fundos de investimentos sob intuito de compensar as perdas nos mercados americano e europeu. Dentre as medidas seguidas frente ao agravamento da crise, a economia brasileira optou por adotar medidas tais como: leilões para venda de dólares com cláusula de recompra e vendas de dólares das reservas e 
no mercado futuro, sucessivas reduções dos depósitos compulsórios, bem como a edição de uma medida provisória ${ }^{3}$ que possibilita ao Banco do Brasil e à Caixa Econômica Federal comprarem instituições financeiras privadas e tornarem-se sócios de empresas construtoras.

Apesar das dificuldades impostas (relacionadas a fatores de ordem econômica, social, política, estrutural e de inserção internacional) à sua economia, o Brasil vem ganhando destaque mundial, levando-se em consideração o grau de investimento financeiro e produtivo que penetra em seu mercado. Pode-se dizer que tal desempenho deve-se, pelo menos em parte, à introdução de mudanças institucionais inseridas a partir da estabilização econômica.

Nesses termos, entre as principais mudanças institucionais e na política econômica verificadas no período compreendido entre 1995 e 2002, destacam-se a adoção de uma política monetária contracionista e taxas de juros elevadas de forma a manter níveis controlados de inflação; a estabilização econômica; a presença de elevados superávits primários a partir de 1999 - maiores dos que os sugeridos pelo FMI - com vistas ao pagamento da dívida pública; e baixos índices de investimento. Como consequiência restaram-se índices de crescimento pífios, e a presença de um modelo concentrador de renda/capital.

Em termos metodológicos, a elaboração do presente artigo viabilizou-se através da realização de um levantamento bibliográfico das principais mudanças institucionais ocorridas entre 1995 e 2002, caracterizando-se, portanto, por uma pesquisa descritiva com base na utilização de dados secundários, cujo intuito foi analisar o comportamento e a tendência demarcada por certas variáveis relacionadas à configuração do regime de Estado, bem como elucidar aspectos importantes e decisivos sobre o desempenho da economia brasileira a partir dos resultados obtidos.

Estruturalmente o presente artigo é composto de quatro partes. Além da presente introdução, na seção 2 é apresentada uma abordagem entre desempenho econômico e a teoria institucionalista, no item 3 são apresentadas as principais mudanças institucionais ocorridas no Estado brasileiro, e, na seção 4 onde são apresentadas as considerações finais.

\footnotetext{
${ }^{3}$ Medida Provisória N. 443 (21 de outubro de 2008) convertida na lei n ${ }^{\circ} 11.908$, de 2009.
} 


\section{DESEMPENHO ECONÔMICO E A TEORIA INSTITUCIONALISTA}

A análise da influência das instituições sobre o desempenho econômico dos países vem ganhando destaque cada vez maior nos estudos de economia e ciência política realizados no Brasil nos últimos anos. O postulado básico de que "as instituições importam" traz à tona a discussão de uma série de questões para explicar, em parte, por que determinadas economias crescem a taxas maiores em relação a outras. Tal realidade decorre do fato de que o meio institucional exerce papel decisivo sobre o desempenho da economia ao induzir inovações tecnológicas, mudanças na organização das firmas, gestão no processo de trabalho e coordenação de políticas macroeconômicas.

Nesse sentido destacam-se as dificuldades na construção de um arcabouço teórico institucionalista definido e convergente entre as diferentes abordagens haja vista a riqueza teórica embutida nesse tema ao tratar a economia de forma processual e evolucionária, cultural e coletiva, interdisciplinar e não preditiva (CONCEIÇÃO, 2002). Segundo tal escola, as relações econômicas não devem apenas ser tratadas como uma "ciência da escolha" protagonizada pela psicologia de um indivíduo concebido como maximizador. Ao conceber o processo econômico pela noção de um "processo de vida", os institucionalistas consideram o mundo como sendo um lugar construído através da experiência, porventura pela razão. Portanto, não se trata de um mundo revelado e eficiente, porém, observável e inconstante, em eterna construção e sujeito à presença de desperdícios e desequilíbrios.

Entre as dificuldades encontradas pela teoria institucionalista, menciona-se a própria definição do conceito de instituições. Na linguagem usual, a palavra "instituições" pode se referir a diferentes coisas, ainda mais quando levado em consideração o fato de serem historicamente determinadas, tornando mais complexa sua caracterização tendo em vista suas especificidades de tempo e lugar.

No entanto, ainda que verificadas diferenças teóricas na definição do que represente as instituições e sua forma de interação no ambiente socioeconômico, é possível aglutinar as distintas abordagens sob certos pontos de confluência que comportam o "paradigma institucionalista". Esse paradigma assenta-se na concepção essencial de que a atividade humana é um ato coletivo e de que os indivíduos superam as suas limitações através da construção de convenções, isto é, de padrões de ação e comportamento resultantes de interações, mais do que de capacidades inatas. $\mathrm{O}$ mundo da ação é um mundo de que faz parte o conflito e a distribuição assimétrica de informação e de poder. 
Trata-se, portanto, do desenvolvimento concebido mediante mudanças institucionais nas organizações do governo, na sociedade civil e nos agentes produtivos, na busca da construção de novas formas de articulação entre essas esferas de maneira a minimizar os custos de transação.

Além disso, a dificuldade em definir e caracterizar o ambiente institucional traz implicações sob o tipo de política a ser desenvolvida. Para Myrdal (1987), o problema em descobrir o campo de interesses econômicos e a viabilização das respectivas políticas, é tolhido quando levada em consideração a possibilidade da ocorrência de modificações institucionais. $\mathrm{O}$ fato de o ambiente institucional não ser determinado e sim mutável, sob várias direções e graus, representa o principal obstáculo nesse tipo de abordagem.

Nesse sentido, destaca-se a Teoria da Regulação, na qual ganharam destaques as ideias de vários autores. De um modo geral, tais objeções pressupõem que as estruturas sociais não são capazes de gerarem automaticamente as condições necessárias a sua própria reprodução, assim como as reproduções das estruturas econômicas, considerando a acumulação de capital um processo conflituoso. Tal fato implica a necessidade de regulação das estruturas econômicas e sociais para neutralizar as tendências à crise e promover um período de crescimento.

Por outro lado, devido ao caráter parcial e provisório da regulação, o processo de acumulação encontra-se passível de instabilidades, crises e transformações. À medida que ocorre a transformação das estruturas voltadas à superação das estruturas atuais, novas fases de acumulação são definidas. A essa sequência histórica de crises e transformações do capitalismo com mudanças qualitativas na dinâmica de acumulação, e principalmente das relações sociais, que as análises da Teoria da Regulação procuram explicar.

Por assim dizer, a abordagem da regulação surgiu da construção de um referencial teórico voltado à análise do desenvolvimento capitalista contemporâneo cujas bases teóricas encontram-se na atualização do instrumental clássico marxista, no que se refere aos conceitos de relações de produção e forças produtivas, da teoria do valor e suas leis tendenciais do modo de produção capitalista. Sendo assim, a análise do desenvolvimento capitalista consolida-se através da proposição de dois conceitos fundamentais - regime de acumulação e modo de regulação - bem como sua recorrência cíclica entre fases de crescimento e de crise.

Esses dois conceitos servem para representar a articulação entre a estrutura produtiva - concebida através do regime de acumulação - e o conjunto de instituições 
econômicas, sociais e políticas que agem para lhe dar estabilidade, representando o modo de regulação. Segundo Faria (1997), a regulação desenvolveu essa tese para dar conta do estado de relativa estabilidade em que muitas vezes se encontram as economias sujeitas ao que Marx qualificou de anarquia do mercado. Nessas circunstâncias, a continuidade da existência de uma estrutura econômica só seria possível através da existência de um conjunto de normas e procedimentos regulatórios capazes de condicionar o comportamento dos agentes econômicos - trabalhadores, empresários, consumidores, administradores públicos, etc - que interagem de forma sistêmica.

Sob o ponto de vista metodológico, essa Escola encontra-se regida por três princípios fundamentais. O primeiro princípio considera que antagonismos sociais que evoluem para formas de movimento, durante tempos, representam fortes polarizações de conflitos. O segundo princípio da análise regulacionista advém da lógica ambivalente oriunda da interação entre economia e política, e sobre a qual as instituições sociais desempenham importante papel como articuladoras. O terceiro princípio diz respeito à relação Estado-economia que enuncia o Estado como um produto dos conflitos inerentes às separações sociais, sobre a qual a regulação é aberta e inacabada em função de as relações sociais privadas estarem constantemente se modificando e adaptando-se às instituições sociais vigentes em determinado local.

Entre as instituições consideradas responsáveis pela regulação dos sistemas econômicos, destacam-se as seguintes formas institucionais: a relação salarial, a moeda, a concorrência, o Estado, a inserção internacional, e a tecnologia, também tratada pelos evolucionistas como uma instituição (CORIAT, DOSI, 1997; HODGSON, 1997). No entanto, além do papel desempenhado pelas instituições no modo de regulação, é necessário pressupor os efeitos que dado regime de acumulação de capital produz acerca da trajetória de crescimento econômico sobre determinado modo de desenvolvimento.

Por outro lado, definir tais condições e as maneira de se chegar a esses patamares não representa tarefa fácil dada a multiplicidade de fatores envolvidos e a complexidade em conciliar a existência de um governo estável que garanta uma política macroeconômica razoável e impulsione a competição no nível macroeconômico. "As políticas que produzem o crescimento podem ser identificadas como aquelas que simultaneamente, geram a estabilidade macroeconômica, estimulam a eficiência microeconômica e abrem a economia para o comércio internacional (DELFIM NETTO, 2005, p.230, grifos do autor)". 
Significa afirmar que o desenvolvimento econômico de qualquer nação não ocorre de forma independente à configuração do seu arcabouço institucional e do contexto internacional ao qual se encontra inserido, e, portanto, devendo esses ser considerados no processo de delimitação do escopo de políticas públicas.

Sendo assim, pressupõe-se como condição necessária para atingir níveis de desenvolvimento mais elevados, a configuração de um conjunto institucional gerador de riquezas não somente concebidas através da modernização da atividade produtiva, mas também através da possibilidade de acesso às vantagens oriundas da constituição desse arranjo sócio-político, formado pelo Estado, o mercado e o sistema político dentre outras esferas que exercem influência sobre a sociedade.

\section{MUDANÇAS INSTITUCIONAIS E O ESTADO BRASILEIRO ENTRE 1995 E 2002}

Tendo em vista a relevância que exercem as instituições sobre o desempenho econômico, justifica-se a relevância em analisa as transformações ocorridas no Estado brasileiro a partir da segunda metade da década de 1990, sinalizando sob que aspectos tais mudanças contribuíram para a configuração de um cenário favorável à superação da crise de 2008.

Entre 1930 a 1960, a presença do Estado fazia-se sentir através do funcionamento das estatais e da intervenção direta, que juntamente com a atuação do capital privado nacional e multinacional, constituíam o chamado "tripé" da economia brasileira. Nesse período, a atuação do Estado-empresário destinava-se a fomentar a oferta de serviços cuja frágil estrutura produtiva privada era carente. Posteriormente, devido ao crescente endividamento e perda da flexibilidade orçamentária, a atuação do Estado foi regredindo e afastando-se de sua função de provedor de bens e serviços para a sociedade.

Apesar do relevante papel desempenhado pelas empresas públicas até o final da década de 1970, a forte intervenção estatal veio acompanhada por uma série de desajustes macroeconômicos, que somados aos fatos da conjuntura internacional, redefiniriam o papel do governo por causa da necessidade de medidas de controle dos gastos e consequente desvio de sua função como produtor.

Com o fim da bipolaridade leste-oeste e a intensificação da globalização, bem como a introdução das mudanças na arquitetura institucional dela decorrente, a lógica de 
desenvolvimento passou por transformações tendo em vista a crescente sobreposição do mercado em relação ao Estado.

Desse modo, percebe-se a relevância de entender as mudanças institucionais ocorridas na economia brasileira e de que maneira essas influenciaram no processo de desenvolvimento do país. Através da macroanálise das particularidades históricas, torna-se possível delinear tendências a partir do comportamento de algumas variáveis que desempenharam importante papel na formulação de políticas direcionadas ao saneamento de deficiências estruturais.

Durante o período compreendido entre 1995 e 2002, por exemplo, a introdução de uma série de mudanças institucionais tornou-se providencial na evolução do cenário nacional até os dias de hoje, destacando-se: a estabilização econômica; a reconstrução da máquina administrativa; a reforma fiscal (ainda que de forma parcial); a consolidação do sistema financeiro; a definição da taxa de câmbio como fator de competitividade e o restabelecimento das linhas de crédito - as quais devido à efetuação sistemática dos juros da dívida acabaram consumindo boa parte do saldo positivo da balança comercial especialmente durante o primeiro mandato do governo Cardoso.

Em relação à estabilização econômica, deve-se ressaltar o fato que se tornou possível em função da implantação do Plano Real e consequente controle da inflação, a qual chegou a atingir uma taxa de 1,7\% em 1998 em contraposição ao índice de 916,4\% em 1994 (segundo dados Ipea). Com o abatimento da hiperinflação, viabilizou-se a criação de um cenário favorável ao crescimento e equilíbrio na conta corrente. Além disso, com a passagem de uma economia hiperinflacionária para um de baixa inflação, o controle sobre a expansão da moeda no sistema bancário passou a ser maior, exigindo capital mínino dos bancos, levando-se em consideração os riscos dos papéis em carteira e as recomendações do Acordo de Basiléia ${ }^{4}$.

A concessão de incentivos fiscais voltados à incorporação de instituições financeiras e os poderes oferecidos ao Banco Central deram-se por conta do exercício de ações preventivas em relação às instituições que apresentavam problemas de liquidez. Através da criação de programas como o PROER (criado em 1995, com objetivo de oferecer assistência financeira aos bancos privados) e o PROES (criado em 1996, destinava

\footnotetext{
${ }^{4}$ Criado em 1988, na cidade de Basiléia (Suíça). Conforme este acordo, foram definidas exigências mínimas de depósito de capital as quais deveriam ser mantidas pelos bancos comerciais, como fator de precaução contra o risco do crédito, limitando a fixação de índices máximos de alavancagem, o qual não poderia ultrapassar 12 vezes o volume do capital e reservas.
} 
recursos voltados ao saneamento dos bancos estaduais), viabilizou-se a consolidação de um sistema financeiro e também sua ampliação em decorrência da entrada de capitais estrangeiros.

Em relação ao ajuste fiscal, através da introdução de alguns aperfeiçoamentos institucionais, como a Lei de Responsabilidade Fiscal, permitiu-se o aumento de competitividade da economia e a tendência de crescimento do PIB.

Apesar de importantes, tais mudanças não esgotam em si o processo reestruturante pelo qual passou a economia brasileira durante os dois mandatos de Fernando Henrique. Dois meses após assumir o poder em 1995, uma série de propostas sobre a emenda constitucional foi encaminhada ao Congresso no intuito de promover o processo de transformação do Estado brasileiro.

Dentre as mudanças promulgadas, já em agosto do mesmo ano, encontravam-se a abertura da exploração do gás natural aos capitais privados mediante concessão; a quebra do monopólio estatal das telecomunicações - medida que facilitaria o processo de privatizações e consequente instalação e ampliação da telefonia fixa e celular e de transmissão de dados; a permissão de navegação de cabotagem por navios de qualquer bandeira (nas condições definidas em lei), e a proposta de "flexibilização do monopólio do petróleo, visando promover a concorrência estatal com empresas nacionais e estrangeiras, nas atividades de exploração, importação e refino, sem, no entanto, que houvesse a privatização dessa estatal.

Em sua essência tais transformações possuíam em comum o fato de pertencerem a um conjunto estratégias a ser implementado gradativamente pelo Estado e que constituía o chamado Plano Diretor da Reforma do Aparelho do Estado. De acordo com o diagnóstico do Plano Diretor, reverter a situação de crise fiscal ao qual se encontrava o país (decorrente da exaustão do processo de substituição das importações) implicaria não somente promover a reestruturação do aparelho de Estado, como também, sua forma de gestão.

O ponto de partida para introdução de inovações encontrava-se na necessidade de diferenciar o aparelho de Estado e suas funções propriamente ditas. Desse modo, julgavase indispensável à consolidação da estabilização econômica a transferência para o setor privado das atividades que pudessem ser realizadas pelo mercado, limitando a atuação governamental à prática burocrática de regulação e coordenação na aplicação de recursos.

Sob tal intuito, era possível verificar a adoção de ações orientadas para os seguintes objetivos: a) o fortalecimento do núcleo estratégico visando ao resgate da capacidade 
reguladora, formuladora e avaliadora das políticas publicas, de maneira a manter as características básicas da administração burocrática; b) a revitalização das autarquias e fundações na forma de Agências Executivas e Reguladoras, caracterizando um novo modelo institucional voltado ao resgate da autonomia administrativa e gerenciamento do desempenho; c) tornar publico a prestação de serviços não-exclusivas de Estado através da disseminação de Organizações Sociais administradas pela sociedade; d) a privatização da produção de bens e serviços para o mercado sob pretexto de que as empresas são mais eficientes quando controladas pelo mercado e administrada privadamente, cabendo ao Estado o papel regulador e transferidor de recursos e não de execução (Ministério do Planejamento, Orçamento e Gestão).

Estruturalmente a reforma contou com a presença de um núcleo estratégico responsável pela reorganização da Presidência e dos ministérios, composto pela Secretaria Geral e a Secretaria de Assuntos Estratégicos. Além disso, outras medidas reforçaram a estrutura de coordenação e controle através da transformação dos secretários-executivos em elementos de ligação informal entre a Presidência da República e os ministros, bem como, a organização de sistemas de planejamento, controle interno e orçamento, contando com a participação dos Ministérios da Fazenda e do Planejamento e Orçamento.

Pretendia- se, desse modo, através da reforma administrativa reestruturar o modelo de gestão sob intuito de promover a superação de obstáculos que limitavam o desenvolvimento econômico respaldada na articulação de um aparelho de Estado ágil e flexível, capaz de articular mercado e sociedade civil.

De tal forma que durante o primeiro mandato de seu governo, Cardoso preocupouse na implementação de ações de alcance estrutural respaldas na aprovação de emendas constitucionais. Entre as principais reformas destacaram-se a previdenciária; a administrativa; o saneamento do sistema financeiro; a adoção da Lei 9.496/97 que privilegiava o refinancimento das dividas dos estados e municípios a partir do reconhecimento de passivos contingentes (os chamados "esqueletos"); e, adoção do programa de privatizações visando o ajuste patrimonial.

Já no segundo mandato verifica-se sua preocupação em introduzir reformas de Estado, sobretudo, na área fiscal quando então foi adotado em 1999, o Programa de Estabilidade Fiscal (PEF). De acordo com tal programa, o ajuste fiscal poderia ser obtido através da redução das despesas financeiras do setor público e o estabelecimento de metas 
de superávit primário sob pretexto de conter a participação da dívida líquida do setor público.

Sendo assim destacaram-se entre importantes transformações vivenciadas pelo Estado brasileiro durante o período em questão:

\section{a) Reforma da Previdência}

O processo de reforma da previdência nacional teve início em 1995 através do envio ao Congresso de uma proposta de emenda constitucional, em que a adoção de medidas prolongou-se até 2002 no sentido de conter os desequilíbrios no sistema e aperfeiçoar a sua gestão.

Tal reforma constituía-se de três estratégias principais orientadas sobre diferentes setores do sistema: i) fortalecimento geral do regime de Previdência Social através de medidas que aumentassem a vinculação entre as contribuições e os benefícios de forma a expandir a cobertura; ii) desenvolvimento do regime privado de previdência complementar, em capitalização facilitando o acesso de grupos excluídos; e iii) ajustamento dos regimes próprios de repartição dos servidores e aplicação aos futuros servidores das regras semelhantes às do regime geral, com instituição do teto e desenvolvimento de esquemas de previdência complementar (PINHEIRO, 2004).

Com a aprovação da emenda constitucional n.20 em 1998, e as alteração nos três regimes previdenciários (privado, público e geral), viabilizou-se a discussão no Congresso Nacional de uma série de projetos de leis complementares e ordinárias que regulamentava matérias específicas entre 1999 e 2001. Sendo assim, conforme salienta Pinheiro (2004, p.226): “A aprovação destes projetos, conjuntamente com a conversão em lei de várias medidas provisórias (MPs) editadas em 1998 e 2000 conformou um novo arcabouço jurídico-institucional de organização do sistema previdenciário".

Através dessas reformas, foi estabelecido no Brasil um sistema baseado no regime geral de repartição que cobria os proventos integrais em quase $90 \%$ da população ocupada no setor formal privado, bem como a criação de mecanismos de desenvolvimento da previdência complementar privada em bases voluntárias. $\mathrm{O}$ fortalecimento de um sistema 
público de repartição estava respaldado na percepção de que a Previdência representava um dos pilares da estabilidade social do país ${ }^{5}$.

Entre as principais mudanças estão a eliminação gradual da aposentadoria proporcional; a restrição à conversão de tempo de serviço especial, trabalhado em condições consideradas penosas, para a aposentadoria por tempo de contribuição; a restrição às aposentadorias especiais e a mudança na regra de cálculo do benefício, com introdução do fator previdenciário ${ }^{6}$.

Ao serem propostas, as medidas de reforma da Previdência tinham por objetivo aumentar a arrecadação, diminuir distorções e desigualdades e conseguir que o período de vida ativa fosse prolongado, de modo que, no serviço público, as aposentadorias não se dariam, na média, com menos de 50 anos de idade, independentemente, do tempo de contribuição.

Sob aspectos gerais, a emenda constitucional remetida em março de 1995 ao Congresso representou de uma tentativa de modificar na Constituição as seguintes regras de aposentadoria: substituição da aposentadoria por tempo de serviço pela aposentadoria por tempo de contribuição; contaria para o recebimento e definição do valor do beneficio além do tempo de serviço a idade, podendo essa sofrer adaptações para adequar-se às realidades demográficas (uma vez que definida através de lei complementar); proibia-se a acumulação de aposentadorias com as remunerações recebidas em função de cargo, emprego ou função pública; proibia-se a aposentadoria proporcional ao tempo de serviço que permitia, por exemplo, que o funcionário se aposentasse depois de trabalhar apenas 20 anos; propunha-se a diminuição da diferença do requisito mínimo de idade entre homens e mulheres para fins de aposentadoria e outras mudanças; ainda que, fossem mantidos os fundamentos do sistema previdenciário, baseado na solidariedade entre as gerações.

\section{b) Refinanciamento das dívidas dos estados e municípios}

\footnotetext{
5 De acordo com o IBGE, para cada pessoa que recebe um prestação da Previdência, há mais 2,5 que indiretamente, também são beneficiadas (PNAD, 2001).

${ }^{6}$ A modificação na regra de cálculo dos benefícios representou um dos principais avanços no período. De acordo com as novas regras, a referência do cálculo para o benefício passou a ser a media das $80 \%$ melhores remunerações observada a partir de julho de 1994 até o momento da aposentadoria. Além disso, passou a ser aplicado ao cálculo um fator calculado com base no tempo de contribuição, idade e expectativa de sobrevida do aposentado. Tal fator acabaria trazendo incentivos à postergação da aposentadoria, uma vez que essa seria progressivamente maior a cada ano de postergação.
} 
O Programa de Apoio Financeiro e de Refinanciamento dos Estados ${ }^{7}$, de 1997, representou uma das mais importantes mudanças do regime fiscal brasileiro desde a Constituição de 1988. O federalismo fiscal brasileiro, até então presente, pautava-se na possibilidade de transferência das dívidas estaduais para o governo federal. E se por um lado tal prática funcionava como instrumento de barganha política do governo federal, por outro lado, criou forte estímulo à irresponsabilidade fiscal nas esferas estaduais (GUARDIA, 2004).

A partir da institucionalização do referido programa, o desequilíbrio fiscal passaria por importantes mudanças sendo a de maior notoriedade o fato de que o refinanciamento das dívidas estaduais passaria a ser condicionado por um severo programa de ajuste fiscal sob pena de que aquele estado que não conseguisse alcançar o planejamento fiscal teria cassado o seu direito de usufruir dos benefícios do refinanciamento.

De acordo com o Programa de Apoio Financeiro e de Refinanciamento da Dívida dos Estados, permitiu-se o refinanciamento da dívida em trinta anos com taxas de juros de $6 \%$ ao ano e correção pelo IGP-DI. Em troca, os estados se comprometiam com o pagamento mínimo da dívida equivalente, em média, a 13\% de sua Receita Corrente Líquida e com a privatização de empresas para o pagamento antecipado de parte da dívida refinanciada pela União.

Como garantia de pagamento da dívida, os estados ofereciam as receitas decorrentes das transferências constitucionais de impostos que recebiam da União, bem como parte de sua própria receita. Em caso de não pagamento, o Tesouro Nacional possui autoridade para reter as transferências constitucionais aos estados ou a bloquear os recursos próprios - basicamente a receita do ICMS - diretamente na conta de cada estado.

\section{c) Ajuste patrimonial e o programa de privatizações}

Ao assumir a presidência em 1995, Fernando Henrique Cardoso ampliou o processo de privatizações nos setores de mineração e serviços públicos, e também de empresas pertencentes a estados e municípios. Entre as intenções dessa conduta, além da necessidade de promover o ajuste fiscal, principalmente nas esferas regionais e municipais, destaca-se a necessidade de agenciar a redução dos espaços fechados e protegidos sobre a ação da concorrência, através da quebra de monopólios e da abertura da economia, de

\footnotetext{
${ }^{7}$ Instituído através da lei n. 9.496.
} 
maneira a oferecer a todos os consumidores maior acesso a bens e serviços de qualidade por menor preço. Essas medidas juntamente com o plano de estabilização econômica deveria permitir o acesso à população de baixa renda ao consumo de bens de consumo nãoduráveis - em particular alimentícios.

Muito embora a intenção das privatizações estivesse relacionada à democratização no acesso aos serviços e mercados proporcionados pela abertura, bem como pela estabilização econômica a partir da redução dos gastos do governo e repasse de dívidas para a iniciativa privada e, consequentemente, exercendo influência sobre o controle inflacionário, deve-se ressaltar que no curto prazo seu efeito não foi favorável. Haja vista o fato de que a privatização reverteu a tendência de criação de empregos no setor público, em vários casos, mesmo antes de as empresas serem privatizadas, o excesso de mão-deobra foi eliminado no intuito de torná-las mais atraentes aos compradores em potencial ${ }^{8}$.

Sob outro enfoque, deve-se levar em conta que a privatização forçou uma revisão das tarifas dos serviços públicos contribuindo na desvalorização da renda, ainda que tenha ampliado o acesso a um número maior de consumidores.

De acordo com Pinheiro (1996) e levando-se em consideração o processo como um todo, pode-se dizer que as privatizações e as reforma regulatórias dos anos 1990 foram responsáveis pelo aumento de produtividade e do investimento em reabilitação e modernização da infraestrutura brasileira, e, logo, à substancial melhoria do desempenho das antigas estatais, no que diz respeito ao lucro líquido, vendas por empregado, investimento e imobilizado.

Contribuiu para essa situação o fato de que o Programa Nacional de Privatização brasileiro ter sido um dos maiores do mundo. Segundo dados do Banco Central, entre 1991 e 2002, o total das receitas com as vendas de empresas estatais a investidores privados alcançou a cifra de $\$ 105$ bilhões, de modo que as maiores vendas foram realizadas em 1997 e 1998, cujos valores atingiram cifras de US\$ 12,3 e US\$ 26,7 bilhões respectivamente.

\footnotetext{
${ }^{8}$ Na rede Ferroviária Federal S.A. cerca da metade dos 40 mil empregados foi demitida mesmo antes da privatização. E, depois de tomar posse os operadores privados da ferrovia reduziram ainda mais o quadro de empregados para cerca de 11.500 , enquanto aumentavam o nível de serviços. Nos maiores portos públicos, a quantidade de empregados foi reduzida de $26.400 \mathrm{em} 1995$ para aproximadamente 5 mil em 1997. No setor de aço a redução de empregados também foi significativa, sendo que na Companhia Siderúrgica Nacional caiu de 24.463 em 1989 para 9.929 em 1998, na Cosipa, de 14.445 para 6.983, e na Usiminas de 14.600 para 8.338 (Baer:2009:328).
} 


\section{d) Saneamento do Sistema Financeiro}

A irresponsabilidade fiscal somada a elevadas taxas de inflação que antecederam o Plano Real, foram determinantes para que muitas instituições financeiras passassem por dificuldades de liquidez e conseqüente intervenção do Banco Central (Bacen) no sistema.

Para isso, basta levar em consideração o fato que, por duas vezes, o Tesouro Nacional viu-se forçado a socorrer o Banco Central no intuito de evitar sua descapitalização, conforme salienta Cardoso:

Vários governos estaduais haviam utilizado os bancos locais para tomar empréstimos que não tinham condições de honrar, sem esquecer que tais bancos emprestaram sem critério ao setor privado dinheiro que se transformou em créditos podres, ou seja, dívidas que as instituições dificilmente conseguiriam receber (CARDOSO, 2006:571).

Nos países emergentes, o interesse pela situação dos sistemas financeiros passou a crescer substancialmente a partir de meados de 1997 em decorrência da eclosão da crise asiática. De acordo com especialistas, entre as principais causas que deram origem à crise deve-se considerar a situação dos bancos. Mediante a possibilidade de obtenção de garantias pelo governo, o sistema financeiro passou a emprestar excessivos volumes de recursos que desencadeariam um processo inflacionário nos preços dos ativos financeiros.

O aumento no valor dos ativos, por sua vez, acabou desencadeando uma melhora nos balanços dos bancos e contribuindo para a obtenção de patamares ainda maiores de empréstimos. No entanto, seria de se esperar que em certo momento, o pessimismo quanto à solvência do sistema tomasse conta da sociedade, desencadeando uma reversão na tendência de alta no valor dos ativos, e, finalmente à deterioração do balanço dos bancos, ratificando a queda no preço dos ativos (PUGA,1998).

No Brasil, uma série de ajustes veio sendo introduzida gradativamente desde a implantação do Plano Real sob intuito de proteger o sistema financeiro nacional dos riscos ocasionados pela globalização financeira, bem como, diferenciá-lo de outras nações emergentes. Entre tais medidas, destacaram-se mudanças na legislação do sistema financeiro brasileiro; concessão de menores volumes de créditos em atraso e em liquidação em relação ao total de créditos concedidos pelos bancos nacionais; entrada de instituições financeiras internacionais as quais contribuíram para dar mais solidez ao sistema além de 
forçar o aumento da eficiência por parte das instituições já estabelecidas no país; a implantação do PROER, em 1995, e do PROES, em 1996; entre outras.

A respeito das mudanças legislativas surgidas no sistema financeiro destacaram-se desde a adoção de medidas em consonância com o Acordo de Basiléia, assim como, àquelas relacionadas à tarifação de serviços bancários. Entre os exemplos podem ser citadas os seguintes aspectos: a) edição da Resolução 2.099 em 1994, a qual estabelecia limites mínimos de capital para a constituição de um banco, além de limites adicionais que variavam de acordo com o grau de risco dos ativos; b) adoção da Medida Provisória 1.179 em 1995, onde foram criados incentivos fiscais para a incorporação de instituições financeiras, permitindo que a instituição incorporadora passasse a contabilizar como perda os créditos de difícil recuperação da instituição adquirida, c) adoção da Medida Provisória 1.182 em 1995, que ampliou os poderes do Banco Central, de maneira que realizasse ações preventivas para sanear o sistema financeiro; d) edição da resolução 2.208 em novembro de 1995 a qual instituiu o PROER; e) publicação da Resolução 2.211 a qual o Banco Central aprovou e estatuto e regulamentou o Fundo Garantidor de Crédito (FGC ${ }^{9}$ ) que estabelecia uma garantia de até $\mathrm{R} \$ 20$ mil por titular para os depósitos e aplicações, nos casos de decretação de intervenção, liquidação extrajudicial, falência ou reconhecimento pelo Banco Central de estado de insolvência da instituição financeira após o Plano Real; f) edição da Resolução 2.212 a qual dificultava a constituição de novas instituições financeiras além de criar incentivos para a fusão, incorporação e transferência de controle acionário; g) publicação da Resolução 2.303 a qual permitia às instituições financeiras a cobrança de tarifas na prestação de serviços, medida considerada necessária em virtude da perda de receitas pelos com a queda da inflação; entre várias outras medidas (PUGA, 1998).

Tais reformas tinham como finalidade principal a de fortalecer e reestruturar o sistema financeiro nacional além de, representarem importantes instrumentos de estabilização econômica especialmente, devido após a perda significativa da renda advinda das transferências inflacionárias - o floating (PUGA, 1998).

\footnotetext{
${ }^{9}$ De acordo com o Fundo Garantidor de Crédito (FGC) todas as instituições exceto as cooperativas de crédito, seriam obrigadas a contribuir com $0,025 \%$ de todos os saldos de todas as contas cobertas pelo fundo (depósitos a prazo, em poupança, conta corrente, títulos cambiais e hipotecários de todas as instituições financeiras até $\mathrm{R} \$ 20$ mil por conta).
} 
Entre outros instrumentos de ajuste do mercado utilizados pelo Banco Central para lidar com os bancos problemáticos, estatais ou privados, destacaram-se: a) liquidação; b) recapitalização; c) fusão e aquisição e d) reestruturação e vendas.

O processo de reestruturação e venda dos bancos estaduais representou um elemento importante para o saneamento do sistema financeiro, cujo desfecho deu-se através da formalização do Programa de Incentivos para a Reestruturação do Sistema Financeiro Público Estadual (Proes). A finalidade do Proes era reduzir o papel do setor público no sistema financeiro através da privatização, extinção ou transformação dos bancos estaduais em agências de desenvolvimento ou instituições não-finaceiras ${ }^{10}$.

\section{e) Programa de Estabilidade Fiscal (PEF)}

Quando foi apresentado à sociedade brasileira em 1999, o Programa de Estabilidade Fiscal (PEF) fundava-se na premissa básica de que o Estado não poderia gastar mais do que arrecadava, sendo, conseguinte, de fundamental importância para a redefinição do modelo econômico brasileiro que houvesse o equilíbrio das contas públicas de forma definitiva.

Para isso seria necessário que se estabelecesse uma trajetória crescente de produção de superávits primários ao longo do triênio 1999-2001, cujo intuito era estabilizar a relação dívida/PIB em torno de 44\% do PIB a partir de 1999, distribuída através dos anos em: 2,6\% em 1999, 2,8\% em 2000 e 3,0\% no ano 2001.

Caso tais medidas não chegassem a ser cumpridas, seria de se esperar para o ano de 1999 uma brutal deterioração nas contas do governo central decorrentes do surgimento de déficit crescentes que poderiam atingir a cifra de $\mathrm{R} \$ 11,6$ bilhões, contra uma necessidade de geração de superávit de $\mathrm{R}$ 16,4 bilhões.

Por outro lado, somente a partir da introdução de mudanças institucionais seria possível promover as transformações necessárias em velocidade e tempo hábil à consolidação de três objetivos básicos do Plano Real: estabilidade da moeda; crescimento

\footnotetext{
10 Entre as opções disponíveis ao governo federal para lidar com bancos problemáticos destacaram-se: primeiro o fato que o governo podia adquirir instituições financeiras estaduais utilizando títulos públicos como moeda na transação; segundo o fato que podia ajudar a transformar os bancos estaduais em instituições não-financeiras ou agências de desenvolvimento; terceiro que podia financiar a reestruturação do banco estadual com o único objetivo de privatizá-lo posteriormente; e quarto, podia financiar até $50 \%$ do custo de reestruturação do banco estatal recapitalizado pelo governo estadual com uma nova administração que assegurasse a operação profissional e responsável do banco reabilitado (Baer, 2009)
} 
sustentado com mudança estrutural e ganhos de produtividade; e a melhoria progressiva das condições de vida da população brasileira (Ministério da Fazenda).

Apesar da deterioração dos índices antes do ajuste, após a adoção de medidas de natureza estrutural foi possível verificar um aumento positivo sobre a participação do PIB em função de tais mudanças - participação de 0,4\% sobre o PIB em 1999 para 1,24 sobre a participação do PIB em 2001 - bem como, devido à redução dos gastos verificada no período (Receita Federal).

Entre as reformas introduzidas no país desde a implantação do Real e que possibilitaram a obtenção de melhorias sobre os indicadores de ajuste fiscal, destaca-se, em grande parte, a sucessão de crises internacionais durante o período, em que contração sobre o crédito global e da liquidez internacional acabou desempenhando papel decisivo na adoção de ajustes estruturais sobre as finanças do Estado brasileiro.

Entre as iniciativas promulgadas pelo PEF, dois conjuntos principais de ações devem ser destacados: a) Agenda de Trabalho, que tinha preocupação de adotar mudanças institucionais que implantassem medidas estruturais favoráveis à adoção apropriada de decisões, procedimentos e práticas fiscais no futuro. Entre tais reformas enfatizam-se a regulamentação da Reforma Administrativa ${ }^{11}$; a aprovação e a regulamentação da Reforma da Previdência Social ${ }^{12}$ e a instituição da Lei Geral da Previdência Pública; as reformas tributária $^{13}$ e trabalhista, imprescindíveis para promover a competitividade do setor produtivo e estimular o crescimento e a geração de empregos; e a Lei de Responsabilidade Fiscal, capaz de instituir ordem definitiva nas contas públicas do conjunto dos Poderes e níveis de governo; e b) Plano de Ação 1999-2001, cujo objetivo era a implantação de medidas de impacto imediato sobre a situação fiscal da época, de forma a assegurar com

\footnotetext{
${ }^{11}$ Tal reforma buscou institucionalizar entre outras medidas: a instituição de limites aplicáveis à folha de pagamentos; demissão por excesso de quadros de trabalho; perda de cargo público por insuficiência de desempenho; e adoção de regime especial no serviço público.

${ }^{12}$ Entre as principais inovações dessa reforma destacaram-se a implantação do Regime Geral da Previdência Social (dentre outras coisas defendia a eliminação da aposentadoria por tempo de serviço; a desconstitucionalização da regra de cálculo do benefício; restrição às aposentadorias especiais; a fixação de limite máximo para benefícios de Legislação Especial), e o Regime de Previdência dos Servidores Públicos (a qual instituía a combinação de limite de idade e tempo de contribuição; restrição às aposentadorias especiais) e o regime de previdência complementar.

${ }^{13}$ De forma geral, a reforma tributária objetivava reduzir e simplificar a cobrança de tributos sobre o consumo. Destacavam-se entre os objetivos da proposta a redução do número de impostos e contribuições sociais incidentes sobre o consumo; a necessidade de tornar a legislação tributária mais simples, de forma a facilitar o cumprimento da obrigação tributária e a redução dos custos públicos e privados sobre a tributação; assegurar a manutenção dos níveis atuais da carga tributária global e o montante de recursos atualmente disponíveis para cada esfera de governo; construir um sistema mais neutro do ponto de vista da alocação dos recursos, visando à eficiência econômica.
} 
êxito a transição para a estabilização definitiva das contas públicas até que o novo ambiente de equilíbrio fiscal promovido pelas reformas estruturais estivesse estabelecido. Destacou-se nesse sentido a elaboração de um programa fiscal de médio prazo visando à obtenção de superávits primários crescentes e suficientes para estabilizar a relação entre a dívida líquida consolidada do setor público e o Produto Interno Bruto. Entre os principais focos de ataque causadores de desequilíbrio físcal estão o déficit dos Sistemas de Previdência e os gastos do Governo Federal. Além disso, o Plano de Ação contemplou a elevação das receitas - ainda que de caráter transitório - destinada fundamentalmente a corrigir os crescentes desequilíbrios da Previdência.

Através da introdução de medidas estruturais e de curto prazo, tornou-se possível a consolidação da estabilidade econômica em partes atribuídas à contenção de especulações contra o Plano Real, como também a redução da taxa de juros e o aumento da poupança interna (de 14,2\% em 1999 para 16,6\% em 2002- IPEA), principalmente devido crescimento da poupança do governo (de 1,8\% durante o período).

Pode-se ainda dizer que devido a esse novo enfoque dado à forma de gerenciamento da contabilidade pública, o impacto sobre as finanças estaduais ainda maiores a partir da aprovação da Lei de Responsabilidade Fiscal (LRF) no ano de 2000, e que proibia novos refinanciamentos de dívidas dos estados e municípios pela União, eliminando definitivamente a possibilidade de novos acordos de refinanciamento, bem como obrigava o cumprimento dos programas de ajustes estabelecidos a partir do Programa de Apoio Financeiro e de Refinanciamento da Dívida dos Estados.

Em contraposição, o governo adotou medidas de aumento da carga tributária, onerando a competitividade produtiva nacional. Entre as alíquotas que apresentaram aumento, destacaram-se o Cofins - de $2 \%$ para $3 \%$ - e a CPMF que além de prorrogada teve aumento de $0,2 \%$ para $0,38 \%$.

Sob aspectos gerais, pode-se dizer que o Brasil apresentou uma trajetória crescente de arrecadação, principalmente a partir do segundo mandato de Cardoso. Devido às circunstâncias de necessidades de financiamento do setor público, ao esgotamento da receitas decorrentes do processo de privatizações, como também a não aprovação em sua íntegra da reforma da previdência, e ao aumento dos gastos do governo em relação às receitas, não sobrou muitas alternativas senão o aumento da cobrança de impostos.

Em parte, a crescente arrecadação tributária esteve relacionada ao aumento da dívida líquida do setor público (DSLP), conforme registrado pelo BACEN nos meses de 
janeiro e fevereiro de 1999, quando então a DSLP aumentou R\$ 110 bilhões - pouco mais de 10,3\% do PIB daquele ano - e de maio a outubro de 2002 - quando a DSLP aumentou cerca de R\$ 200 bilhões, ou pouco mais de 13,5\% do PIB daquele ano. Em ambos os casos, a DSLP elevou-se porque partes consideráveis da dívida mobiliária brasileira, na casa dos 30\%, de acordo com dados da Secretaria do Tesouro Nacional (STN), estavam atreladas ao dólar em contextos de elevada depreciação da taxa de câmbio (IPEA, 2009).

\section{CONSIDERAÇÕES FINAIS}

Sob aspectos gerais, conclui-se que os dois governos de Fernando Henrique Cardoso foram bastante diferentes entre si no que se refere à configuração do Estado. Se durante o primeiro, destoava-se, entre as principais características, a presença de uma política cambial rígida, crescente dependência do financiamento externo e um desequilíbrio fiscal agudo; por outro lado, verifica-se no segundo mandato a presença de um regime de câmbio flutuante, redução do déficit em conta corrente e ajuste fiscal.

Como denominador comum a ambos os governos, cabe mencionar a preocupação no combate à inflação, bem como a contínua expansão do gasto público. Destacaram-se como fatores relevantes na consolidação da estabilidade econômica a implementação de um programa de reestruturação administrativa baseado fundamentalmente na austeridade fiscal composto por um elenco bastante robusto de importantes mudanças estruturais como a Lei de responsabilidade fiscal; a reforma parcial da Previdência Social; o ajuste fiscal dos estados; o fim dos monopólios estatais nos setores de telecomunicações e de petróleo; e a reinserção do Brasil no cenário internacional através da obtenção de fluxos de investimento externo direto.

A estratégia definida sob tais circunstâncias possuía suas bases na necessidade de promover um rápido ajuste nos fluxos de receitas e despesas da União - sob intuito de aumentar o superávit primário no exercício financeiro de 1999; promover a mudança nos procedimentos de elaboração e execução do orçamento que passariam a ser subordinados aos objetivos da política macroeconômica; bem como a implementação de reformas estruturais que permitissem assegurar, ao longo do tempo, o equilíbrio das contas públicas e que através de uma série de fatores, conforme anteriormente mencionados, contribuíram a constituição de um cenário mais propicio à superação da crise mundial de 2008. 


\section{REFERÊNCIAS}

BAER, W. A economia brasileira. 3 ed. São Paulo: Nobel, 2009.

BACEN-BANCO CENTRAL DO BRASIL - Disponível em <http//www.bcb.gov.br>, vários acessos.

CARDOSO, F.H. A arte da política: a história que vivi. Rio de Janeiro: Civilização Brasileira, 2006.

CONCEIÇÃO, O.A.C. Instituições, crescimento e mudança na ótica institucionalista. Teses FEE, n.1, Porto Alegre, 2002.

DELFIM NETTO, A. Meio século de economia brasileira: desenvolvimento e restrição externa. In: GIAMBIAGI, F. e VILLELA, A.(org). Economia Brasileira Contemporânea (1945-2004). Rio de Janeiro: Elsevier, 2005.

FARIA, L.A.E. Centro, periferia e dependência: a crise do fordismo lá e cá. Ensaios FEE: Porto Alegre, v.18, n.2, 1997.

GREENSPAN, Alan. A era da Turbulência: aventuras em um novo mundo. Rio de Janeiro: Elsevier, 2008.

GUARDIA, E. (ORG). Reformas no Brasil: balanço e agenda. Rio de Janeiro: Nova Fronteira, 2004.

IPEA - INSTITTUTO DE PESQUISA ECONOMICA APLICADA. Brasília. Base de dados: IPEADATA. Disponível em <http://www.ipeadata.gov.br/ipeaweb.dll/ipeadata>. Vários acessos (2010)

MYRDAL, Gunnar (1987). Aspectos políticos da teoria econômica. São Paulo: Abril Cultural. (Os Economistas). Originalmente publicado em 1953.

PINHEIRO, A.C. Por que o Brasil cresce pouco? (In) GIAMBIAGI, F., REIS. J.G., URANI, A. (ORG). Reformas no Brasil: balanço e agenda. Rio de Janeiro: Nova Fronteira, 2004.

Privatização no Brasil: Por quê? Até onde? Quando? (org) GIAMBIAGI, F. MOREIRA, M.M. A economia brasileira nos anos 90. Rio de Janeiro, BNDES, 1999.

PUGA, F.P. Sistema financeiro brasileiro: reestruturação recente, comparações internacionais e vulnerabilidade à crise cambial. Textos para discussão: BNDES, 1998. Disponível em <http://www.bndes.gov.br/SiteBNDES/bndes/bndes_pt/Institucional/Publicacoes/Consulta _Expressa/Tipo/Textos_para_Discussao/>. Acessado em 2009

SECRETARIA DA RECEITA FEDERAL. Dados disponíveis em <http://www.receita.fazenda.gov.br/Aduana/Relatorios.htm>. Acessado em 2010. 
SECRETARIA DO TESOURO NACIONAL - STN (2009). Estatísticas. Brasília. Disponível em <http://www.stn.fazenda.gov.br>. Vários acessos. 